\title{
Yoga and Health
}

\author{
Siddappa Naragatti \\ Yoga Therapist, CCRYN, New Delhi. \\ DOI: https://doi.org/10.24321/2394.6547.201804
}

\begin{abstract}
Yoga is an ancient solution to modern problems. It has gained a lot of popularity around the world during the last century. Yoga, as many people often subscribe to, is not merely a method to attain mental peace, but also a powerful method to get rid of ignorance which causes various kinds of suffering in human life. 'Education is the manifestation of the divinity already in man.' It emphasizes on life-building, man-making, character-making, assimilation of ideas. The very essence of education is concentration of mind, not the collecting of facts. In ancient times, people used to go to sages to learn wisdom and to get answers to the fundamental questions of life. This was seen in all ancient civilizations - Greece, India, and China, in particular. However, over the centuries education has retreated from that position. We no longer claim to give wisdom, we give only information, our schools no longer give moral and spiritual values, only secular subjects are taught. The very much need of the education system is the education by which character is formed, strength of mind is increased, the intellect is expanded, and by which one can stand on one's own feet. Yoga is not simply Asanas and Pranayamas. It also involves certain ethical practices. These ethical practices are known as Yamas and Niyamas. No educational system is effective unless it incorporates into itself these ethical practices.
\end{abstract}

Keywords: Yoga, Health, Education, Ethics

\section{Introduction}

Yoga is an ancient Indian practice and a way of life that includes regulated breathing, maintaining various postures and meditation. The word "yoga" comes from Sanskrit and means "to yoke" or join. The focus is on the union of mind and body or the harmonic synchronization of body, breath, and mind. Patanjali formally described the practice of yoga in the treatise Yoga. ${ }^{33} \mathrm{He}$ defined yoga as the process of eliminating all thoughts in the mind and allowing it to settle down to silence. Attainment of such a balance ultimately leads to a balanced and healthy mind and body. ${ }^{20}$ Yoga is a systematic process of calming down the mind and Maharshi Patanjali advocated systematic practices which include yama (ethical disciplines), niyama (purificatory practices), asanas (postures), pranayama (regulated nostril breathing), pratyahara (introspection), dharana (attention/concentration), dhyana (meditation), and samadhi (detached awareness of self) aimed towards attainment of self-realization or the inner blissful state. Among these, asanas, pranayama, and meditation are popular and have been used as a therapy for decades.

Health is precocious treasure of an individual who is looking to lead a meaningful life. In the current scenario, it is quite challenging to enjoy the best productivity for a person through the good physical and mental health.

The advancement in science and technology has increased the sedentary and semi-sedentary lifestyle leading to lack of physical activity. In addition to this, stressful situations are also contributing a lot for the rise in psychosomatic diseases.

World Health Organization and other policy makers on healthcare system are striving a lot to adopt holistic healthcare measures which can be effective in the prevention of lifestyle and psychosomatic diseases such as hypertension, diabetes mellitus, obesity, etc.

E-mail Id: siddappa.naragatti@gmail.com

Orcid Id: https://orcid.org/0000-0001-8644-4160

How to cite this article: Naragatti S. Yoga and Health. J Adv Res Ayur Yoga Unani Sidd Homeo 2018; 5(1): 11-14. 
Ashtanga yoga of sage Patanjali is one of the most comprehensive methodologies for the development of holistic healthcare model-based sustainability for global health, peace and environmental concerns.

The research in yoga has shown that its therapeutic values are helpful for health promotion and disease prevention. The principles and practices of Yoga in the form of therapy are being used as preventative, complementary and alternative medicine in dealing with various physical and mental disorders.

Social approach, cost-effective and eco-friendly characteristics are the important factors for sustainability of any system and these are effectively achieved in yoga for gaining numerous health benefits on multiple dimensions of health concepts.

\section{Ashtanga Yoga of Maharishi Patanjali}

The classical work of Yoga sutras of Sage Patanjali is one of the most authorities guide on the principles and practices of Yoga which is based on the Samkhya philosophy. Ethical preparation, control of the mind and body and development of the spiritual journey is explained in the Yoga sutras. The practice of Ashtanga Yoga is useful in the reduction of the impurities and attainment of the highest wisdom. They are:

- Yama: Universal morality

- Niyama: Personal observances

- Asanas: Body postures

- Pranayama: Breathing exercises, and control of prana

- Pratyahara: Control of the senses

- Dharana: Concentration

- Dhyana: Devotion, meditation on the divine

- Samadhi: Union with the divine

\section{Relevance of Yoga in Social Health}

The principles of Yoga called as social code of conduct and personal observances are effective in purifying the impurities in moral behavior which are more serious issues for the social health. Will power, intellect, and stability on the emotions is attained through the practice of these disciplines. The social harmony and self-acceptance level improves for the wellness of the society.

\section{Promotion of Physical Health}

Yoga interventions are known to affect physical health by improving muscular fitness, ${ }^{5,6,36}$ flexibility, ${ }^{2,8,22,25}$ increasing motor control and performance, ${ }^{29,35}$ alter metabolism and autonomic function ${ }^{35}$ and improve ventilatory functions of the lungs including a prolongation of breath holding time..$^{1,12}$

The practices of Asanas and pranayama are effective for improvement of strength and flexibility, enhance the joints range motions, blood circulation, and purification of the gastro-intestinal tract. These health benefits are well known for enhancing the functional capacity of different systems in our body such as improved digestion, lung capacity, and stimulation of peristalsis.

\section{Yoga for Mental Health}

The inner conflicts, stressful conditions are known to affect our mental health. The philosophical foundations of yogic principles and practices of Pranayama and meditation harness the mental harmony to develop the peace of mind, serenity which is an antidote in the prevention of mental health issues. The altered conditions of brain waves pattern to Alpha dominance is one of the significant change taking place during meditation and relaxation techniques. Alpha waves are associated with felling of wellbeing and calmness.

A study by Subramanya ${ }^{32}$ showed a significant improvement in the scores of all sections of the Wechsler memory scale (WMS) which assessed (i) attention and concentration (digit span forward and backward), and (ii) associate learning following both cyclic meditation (CM) and supine rest (SR), but the magnitude of change was more after CM compared to after SR. The state anxiety scores decreased after both CM and SR, with a greater magnitude of decrease after $\mathrm{CM} .^{32}$ Studies by Naveen ${ }^{23}$ and Joshi ${ }^{13}$ showed increase in the spatial memory scores immediately before and after 45 minutes and also following ten days of different Pranayama practices. ${ }^{13,23}$ Studies have also shown to reduce anxiety and depression among both healthy as well as diseased conditions. ${ }^{11,15,17,21,39}$

\section{Regulation of Emotions}

The concept of afflictions and attitude corrections in Yoga philosophy significantly contributes for emotional health. The guidelines recommend a person to inculcate the perceptions on the basis of the phenomenal nature and its purposes with a dispassionate feeling. This is an important teaching for maintaining stable emotional health.

\section{Health in Spirituality}

Yoga is essentially a spiritual discipline. This concept of the practical realization of the spiritual truth is one of the salient features of the Indian system of philosophies. The sages and saints have walked the great path to fulfill the aim of the meaningful life which is filled with inner harmony and happiness.

\section{Yoga in Disease}

Several studies suggest that yoga significantly improves risk factors for CVD like body weight, lipid profile, blood pressure, smoking, psychosocial stress and type 2 diabetes mellitus. ${ }^{10,16,30,34}$ The possible mechanism of reduction of blood pressure is considered to be reduced sympathetic 
activity and restoration of baro-receptor sensitivity by yoga. ${ }^{31}$ Regular practice of Yoga has shown to significantly reduce early atherosclerosis as assessed by carotid intimal medial thickness. ${ }^{4,18}$ Similarly, regular practice of Yoga with use of low-fat vegetarian diet resulted in retardation of progression and even regression of coronary obstructions as compared to usual care control group in angiographic ally detected coronary artery disease. ${ }^{7,18,24}$ Small clinical trials have shown benefits of yoga in patients with diabetes, ${ }^{3,10}$ and a systematic review found that yoga improved metabolic risk factors. ${ }^{9}$ Integrated yoga program has been shown to be helpful in reducing both post-chemotherapy nausea and anticipatory nausea and vomiting. This has been attributed to stress-reduction effects of yoga intervention. ${ }^{26}$ Furthermore, yoga has also been shown to improve postoperative outcomes such as duration of hospital stay, facilitate wound healing and reduce number of days of drain retention apart from having potent anxiolytic effects and antidepressant effects. ${ }^{27,28}$ Integrated yoga program has also been shown significant decrease in mean salivary cortisol levels at $0600 \mathrm{hrs}$, pooled diurnal mean cortisol, perceived stress along with significant decrease in anxiety, depression ${ }^{37}$ and significant improvement in positive affect, emotional function and cognitive function, and decrease in negative affect, psychological distress, insomnia, fatigue and appetite loss. ${ }^{37}$

\section{Conclusion}

In a nut shell, the philosophy and practices of Yoga are quite relevant in the modern life and they play significant role in the prevention of disease and health promotion through sustainable approach.

\section{Conflict of Interest: None}

\section{References}

1. Bhole MV, Karambelkar PV, Gharote ML. Effects of yoga practices on vital capacity - A preliminary communication. Indian J of Chest Disease 1970; 12(1\&2): 1-4.

2. Caren Lau, Ruby Yu, Jean Woo. Effects of a 12week hatha yoga intervention on cardiorespiratory endurance, muscular strength and endurance, and flexibility in Hong Kong Chinese Adults: A controlled clinical trial. Evid Based Complement Alternat Med 2015; Jun 8: 958727.

3. Cohen DL, Bloedon LT, Rothman RL et al. lyengar yoga versus enhanced usual care on blood pressure in patients with prehypertension to stage I hypertension: A randomized controlled trial. Evidencebased Complementary and Alternative Medicine 2011; 546428.

4. Fields JZ, Walton KG, Schneider RH et al. Effect of a multimodality natural medicine program on carotid atherosclerosis in older subjects: A pilot trial of
Maharishi Vedic Medicine. Am J Cardiol 2002; 89: 952e958.

5. Gharote ML. Physical fitness in relation to the practice of selected yogic exercises. Yoga-Mimamsa 1976a; 18(1): 14-23.

6. Gharote ML, Ganguly SK, Moorthy AM. Effect of yogic training on minimum muscular fitness. Yoga-Mimamsa 1976; 18(3\&4): 1-20.

7. Gupta SK, Sawhney RC, Rai L et al. Regression of coronary atherosclerosis through healthy lifestyle in coronary artery disease patients. Mount Abu open heart trial. Indian Heart J 2011; 63: 461-69.

8. Govindarajulu N, Gannadeepam J, Bera TK. Effect of yoga practices on flexibility and cardiorespiratory endurance of high school girls. Yoga-Mimamsa 2003; 35(1\&2): 64-70.

9. Innes KE, Bourguignon C, Taylor AG. Risk indices associated with the insulin resistance syndrome, cardiovascular disease, and possible protection with yoga: A systematic review. Journal of the American Board of Family Practice 2005; 18(6): 491-519.

10. Jain SC, Uppal A, Bhatnagar SO et al. A study of response pattern of non-insulin dependent diabetics to yoga therapy. Diabetes Research and Clinical Practice 1993; 19(1): 69-74.

11. Javnbakht M, Hejazi Kenari R, Ghasemi M. Effects of yoga on depression and anxiety of women. Complement Ther Clin Pract 2009 May; 15(2): 102-04.

12. Joshi LN, Joshi VD, Gokhale LV. Effect of short term 'Pranayam' practice on breathing rate and ventilatory functions of lung. Indian J Physiol Pharmacol 1992; 36 (2): 105-08.

13. Joshi M, Telles S. Immediate effects of right and left nostril breathing on verbal and spatial scores. Indian J Physiol Pharmacol 2008; 52(2): 197-200.

14. Khalsa SBS. Why do yoga research: who cares and what good is it? Int J Yoga Ther 2007; 17: 19-20.

15. Katzman MA, Vermani M, Gerbarg PL et al. A multicomponent yoga-based, breath intervention program as an adjunctive treatment in patients suffering from generalized anxiety disorder with or without comorbidities. Int J Yoga. 2012 Jan; 5(1): 57-65.

16. Mahajan A, Reddy K, Sachdeva U. Lipid profile of coronary risk subjects following yogic lifestyle intervention. Indian Heart J 1999; 51: 37-40.

17. Malathi A, Damodaran A. Stress due to exams in medical students: role of yoga. Indian J Physiol Pharmacol. 1999; 43: 218-24.

18. Manchanda SC, Mehrotra UC, Makhija A et al. Reversal of early atherosclerosis in metabolic syndrome by yoga: a randomized controlled trial. J Yoga Phys Ther 2013; 3: 132. http://dx.doi.org/10.4172/2157-7595.1000132.

19. Manchanda S, Narang $R$, Reddy $K$ et al. Retardation of coronary atherosclerosis with yoga lifestyle intervention. J Assoc Phys India 2000; 48: 687-94.

20. McEwen BS. Central effects of stress hormones in 
health and disease: Understanding the protective and damaging effects of stress and stress mediators. Eur J Pharmacol 2008; 583: 174-85.

21. Michalsen A, Grossman P, Acil A et al. Rapid stress reduction and anxiolysis among distressed women as a consequence of a three-month intensive yoga program. Med Sci Monit 2005; 11(12): 555-61.

22. Moorthy AM. Effect of selected yogic asanas and physical exercises on flexibility. Yoga Review 1982; 2(3): 161-66.

23. Naveen KV, Nagarathna R, Nagendra HR et al. Yoga breathing through a particular nostril increases spatial memory scores without lateralized effect. Psychological Reports 1997; 81: 555-61.

24. Ornish D, Brown SE, Scherwitz LW et al. Can lifestyle changes reverse coronary heart disease? The lifestyle heart trial. Lancet 1990; 336: 129-33.

25. Polsgrove MJ, Eggleston BM, Lockyer RJ. Impact of 10-weeks of yoga practice on flexibility and balance of college athletes. Int J Yoga 2016 Jan-Jun; 9(1): 27-34.

26. Raghavendra RM, Nagarathna R, Nagendra HR et al. Effects of an integrated yoga program on chemotherapy induced nausea and emesis in breast cancer patients. Eur J Cancer Care 2007; 16: 462-74.

27. Raghavendra RM, Nagarathna R, Nagendra HR et al. Influence of yoga program on post operative outcomes and wound healing in early operable breast cancer patients undergoing surgery. International Journal of Yoga 2008; 1: 6.

28. Raghavendra RM, Nagarathna R, Nagendra HR et al. Anxiolytic effects of a yoga program in early breast cancer patients undergoing conventional treatment: a randomized controlled trial. Complementary Therapies in Medicine 2009; 17: 1-8.

29. Sahu RJ, Bhole MV. Effect of two types of pranava (Omkar) recitation on psychomotor performance. Yoga-Mimamsa 1983b; 22(3\&4): 23-29.

30. Schmidt T, Wijga A, Von Zur Mu“ hlen A et al. Changes in cardiovascular risk factors and hormones during a comprehensive residential three month kriya yoga training and vegetarian nutrition. Acta Physiol Scand Suppl 1997; 640: 158-62.

31. Selvamurthy W, Sridharan K, Ray US et al. A new physiological approach to control essential hypertension. Indian J Physiol Pharmacol 1998; 42: 205-13.

32. Subramanya P, Telles S. Effect of two yoga-based relaxation techniques on memory scores and state anxiety. Biopsychosoc Med. 2009 Aug 13; 3:8.

33. Taimini IK. The science of yoga. Madras: The Theosophical Publishing House 1961.

34. Tang YY, Tang R, Posner MI. Brief meditation training induces smoking reduction. Proc Natl Acad Sci USA 2013; 110: 13971-75.

35. Telles S, Nagarathna R, Nagendra HR. Breathing through a particular nostril can alter metabolism and autonomic activities. Indian J Physiol Pharmacol 1994; 38: 133-37.

36. Tran MD, Holly RG, Lashbrook J et al. Effects of hatha yoga practice on the health-related aspects of physical fitness. Prev Cardiol 2001 Autumn; 4(4): 165-70

37. Vadiraja HS, Rao RM, Nagarathna R et al. Effects of yoga program on mood and cortisol rhythms in breast cancer patients on radiotherapy: a randomized controlled trial. Integrative Cancer Therapies 2009; 8: 37-46.

38. Vadiraja HS, Rao RM, Nagarathna R et al. Effects of yoga program on quality of life and affect in early breast cancer patients undergoing adjuvant radiotherapy: a randomized controlled trial. Complementary Therapies in Medicine 2009; 17: 274-80.

39. Waelde LC, Thompson L, Gallagher-Thompson D. A pilot study of a yoga and meditation intervention for dementia caregiver stress. J Clin Psychol 2004 Jun; 60(6): 677-87.

Date of Submission: 2018-03-22 Date of Acceptance: 2018-04-24 